Check for updates

Cite this: Chem. Sci., 2019, 10, 7068

๑ All publication charges for this article have been paid for by the Royal Society of Chemistry

\section{An inorganic prodrug, tellurium nanowires with enhanced ROS generation and GSH depletion for selective cancer therapy $\dagger$}

\author{
Ying Wu, ${ }^{a}$ Tao Guo, ${ }^{a}$ Yuan Qiu, ${ }^{a}$ Yan Lin, ${ }^{a}$ Yunyan Yao, ${ }^{a}$ Weibin Lian, ${ }^{b}$ Lisen Lin, ${ }^{c}$ \\ Jibin Song $\mathbb{D}$ *a and Huanghao Yang (D) *a
}

\begin{abstract}
Organic prodrugs have been widely reported to avoid side effects and have been applied for precise tumor therapy in recent years. However, inorganic nano-prodrugs with localized generation of toxic products in the tumor have not been reported. Herein, we report an inorganic nano-prodrug, tellurium nanowires (TeNWs), that generate toxic $\mathrm{TeO}_{6}{ }^{6-}$ triggered by hydrogen peroxide $\left(\mathrm{H}_{2} \mathrm{O}_{2}\right)$ for highly selective cancer chemotherapy. Bovine serum albumin and dextran conjugate coated TeNWs, with a length of $\sim 82 \mathrm{~nm}$ and a width of $\sim 7 \mathrm{~nm}$, showed high stability in physiological medium. The interaction between TeNWs and intracellular $\mathrm{H}_{2} \mathrm{O}_{2}$ produces toxic $\mathrm{TeO}_{6}{ }^{6-}$ molecules greatly enhanced ROS generation, and the reaction product, verified as $\mathrm{TeO}_{6}{ }^{6-}$, would react with glutathione $(\mathrm{GSH})$ and thus decrease intracellular GSH levels, which greatly increases ROS levels in the tumor. Importantly, TeNWs selectively kill cancer cells by caspase-independent autophagic death and apoptosis, as well as exerting an immune response, while not affecting normal cells due to the high $\mathrm{H}_{2} \mathrm{O}_{2}$ levels in cancer cells. Moreover, after the sequential reaction with $\mathrm{H}_{2} \mathrm{O}_{2}$ and $\mathrm{GSH}$, TeNWs were dissociated into small molecules and could be rapidly and completely removed from the body. Both in vitro and in vivo experiments indicate that TeNWs are a promising inorganic nano-prodrug that exerts good selective therapeutic effects on tumors.
\end{abstract}

Received 4th March 2019 Accepted 4th June 2019

DOI: 10.1039/c9sc01070j

rsc.li/chemical-science closely correlated with tumor cell proliferation, infiltration, and metastasis. Thus, tumor cells are far more sensitive to $\mathrm{H}_{2} \mathrm{O}_{2}$ than normal cells and cannot tolerate either excessive increase or excessive decrease of the $\mathrm{H}_{2} \mathrm{O}_{2}$ content, both of which lead to cancer cell apoptosis. ${ }^{19}$ Previously, a number of $\mathrm{H}_{2} \mathrm{O}_{2}$-dependent or $\mathrm{H}_{2} \mathrm{O}_{2}$-activated nanosystems have been described for tumor diagnosis and imaging, ameliorating tumor hypoxia, enhancing PDT, controlled drug release, and treatment of specific diseases. ${ }^{1,20-24}$ However, these systems mainly focused on $\mathrm{H}_{2} \mathrm{O}_{2}$-triggered drug release or enhanced cancer therapy, in response to external treatment, for which nanocarriers may also be toxic. ${ }^{25,26}$ Cerium oxide nanoparticles exhibited potential as antioxidant or radioprotective agents for biological applications in cancer therapy. Gold nanocrystals, such as gold nanoparticle and gold nanorods, have been widely used as a carrier of drugs and photothermal agents for cancer therapy. Even if they are widely used, their potential biological toxicity or metabolism in vivo cannot be concealed. It is necessary and very meaningful to design a nanoplatform of a $\mathrm{H}_{2} \mathrm{O}_{2}$ stimulated nano-prodrug with the ability to directly kill tumor cells after reacting with $\mathrm{H}_{2} \mathrm{O}_{2}$. In theory, such a nanoplatform can achieve a drug utilization rate of $100 \%$ of the nanomaterials accumulated in tumor cells.

The hormesis effect explains why small doses of highly toxic arsenic trioxide can be used to treat diseases. ${ }^{27}$ As a metalloid element, tellurium ${ }^{28}(\mathrm{Te})$ has similar chemical properties to selenium ${ }^{29}$ which is also highly toxic. At the same dose, the 
toxicity of the elemental form of selenium is higher than that of tellurium; however, selenium has a large number of related compounds that have been applied in biological applications. $^{30-32}$ It should be pointed out that unlike selenium, the application of Te nanomaterials in biological applications still needs to be explored. ${ }^{33-35}$

Considering that tellurium compounds are much more toxic than the pure element (e.g. the toxicity of telluric acid is 10 times higher than that of Te), ${ }^{\mathbf{3 4}, 36}$ herein, for the first time, a new type of Te nanowire (TeNW) was developed that can generate ROS triggered by $\mathrm{H}_{2} \mathrm{O}_{2}$ and shows excellent efficacy in cancer therapy (Fig. 1). TeNWs with a length below $100 \mathrm{~nm}$ have high stability in vivo. In the presence of $\mathrm{H}_{2} \mathrm{O}_{2}$, TeNW would produce the toxic molecule $\mathrm{TeO}_{6}{ }^{6-}$. Moreover, the product $\mathrm{TeO}_{6}{ }^{6-}$ interacts with GSH and decreases the intracellular GSH level, which further increases ROS levels and enhances the therapeutic effect. Interestingly, TeNW can selectively kill cancer cells and have negligible effects on normal cells, due to their ultralow $\mathrm{H}_{2} \mathrm{O}_{2}$ levels. Bovine serum albumin (BSA) and dextran conjugate (BSA-dextran) ${ }^{37}$ coated TeNW showed high stability and high cancer therapeutic efficacy in vivo.

\section{Results and discussion}

\section{Preparation and characterization of Te nanowires}

TeNWs were first synthesized in an aqueous solution in the presence of BSA-dextran. The synthesis mechanism can be presented with the following four reaction equations (eqn (1)(4)):

$$
\begin{gathered}
4 \mathrm{NaBH}_{4}+2 \mathrm{Te}+7 \mathrm{H}_{2} \mathrm{O} \rightarrow 2 \mathrm{NaHTe}+\mathrm{Na}_{2} \mathrm{~B}_{4} \mathrm{O}_{7}+14 \mathrm{H}_{2} \\
\mathrm{Na}_{2} \mathrm{~B}_{4} \mathrm{O}_{7}+2 \mathrm{NaHTe}+2 \mathrm{Te}+5 \mathrm{H}_{2} \mathrm{O} \rightarrow 2 \mathrm{Na}_{2} \mathrm{Te}_{2}+4 \mathrm{H}_{3} \mathrm{BO}_{3} \\
\mathrm{Na}_{2} \mathrm{Te}_{2}+2 \mathrm{H}_{2} \mathrm{O} \rightarrow 2 \mathrm{a}-\mathrm{Te}+2 \mathrm{NaOH}+\mathrm{H}_{2} \\
\mathrm{a}-\mathrm{Te} \rightarrow \mathrm{t}-\mathrm{Te}
\end{gathered}
$$

Prior to the reaction in eqn (3), BSA-dextran was dissolved in water which served as a template to control the morphology of nanowires. Due to its steric hindrance, BSA-dextran can limit the

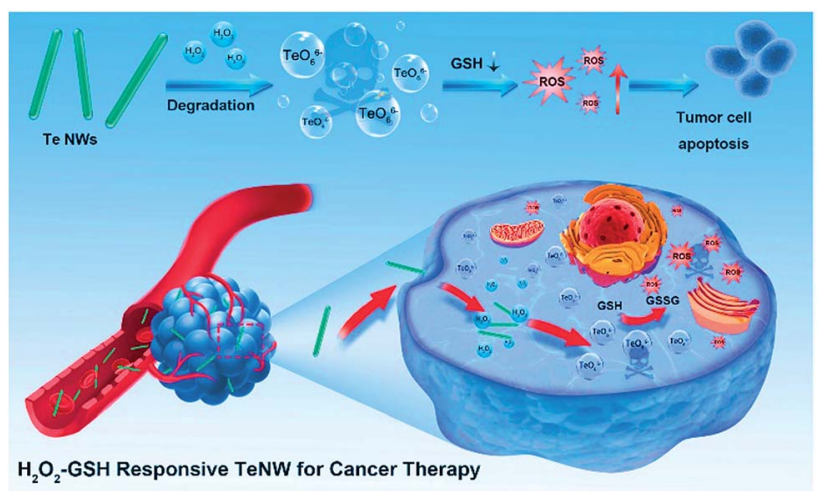

Fig. 1 Schematic illustration of the step-by-step $\mathrm{H}_{2} \mathrm{O}_{2} / \mathrm{GSH}$-activatable inorganic nano-prodrug TeNWs for highly selective cancer therapy. growth of Te to a one-dimensional trend. ${ }^{38}$ TeNWs were directly synthesized from Te powder and $\mathrm{NaBH}_{4}$, resulting in a thick, uneven sized rod shape with poor water solubility (Fig. S1a†). After the addition of BSA, a slim shape with high water solubility was obtained (Fig. S1 $\mathrm{b}_{\dagger}^{\dagger}$ ). If dextran was added to the solution, TeNWs with a small size and poor dispersibility were obtained (Fig. S1c $\dagger$ ). BSA-dextran plays an essential role in the synthesis of TeNWs. BSA-dextran has similar properties to polyethylene glycol in vivo, which increased the stability and biocompatibility of TeNWs.

The as-prepared TeNWs have a linear structure with a high aspect ratio and dimensions of $\sim 82 \mathrm{~nm}$ length and $\sim 6.4 \mathrm{~nm}$ width, as displayed in the transmission electron microscopy (TEM) images in Fig. 2a and DLS (Fig. S2 $\dagger$ ). The high-resolution TEM image of TeNWs shows a characteristic spacing of 5.90, 3.97, and 3.21 ̊ for the (001), (100), and (101) lattice planes, respectively (Fig. 2b). The TeNW is a single crystal as indicated by the electron diffraction pattern (Fig. 2c). X-ray diffraction (XRD) results are consistent with the standard card of Te (PDF: 86-2268) (Fig. 2d). Energy-dispersive X-ray spectroscopy (EDXS) results confirm the presence of Te, C, N, and finite O elements (Fig. 2e). The X-ray photoelectron spectroscopy (XPS) spectrum shows the typical peaks of Te, C, N, O, and S (Fig. S3 $\dagger$ ), combined with the binding energy of $\mathrm{Te}(0) 3 \mathrm{~d}$ (Fig. 2f), which further confirmed the successful synthesis of TeNWs. The $\mathrm{C}, \mathrm{N}$, and $\mathrm{O}$ elements may be originating from glycated albumin, which was added at the time of synthesis, confirming that TeNWs were coated with BSA-dextran. The FTIR spectra of TeNWs and BAS-dextran were tested (Fig. S4†). Based on the peak intensity ratio, it can be concluded that BSA-dextran may interact with Te through several types of bonds including $\mathrm{N}-$ $\mathrm{H}, \mathrm{N}-\mathrm{C}, \mathrm{C}-\mathrm{O}$, and $\mathrm{C}=\mathrm{O}$. It is worth mentioning that BSA-dextran coated TeNWs exhibited a high dispersibility in water and had much higher stability in water, PBS, 1640 medium, and FBS, showing good dispersion without aggregation even after 30 days of incubation (Fig. S5-S7†).

\section{Sequential $\mathrm{H}_{2} \mathrm{O}_{2}$ and GSH triggered dissociation of TeNWs to toxic molecules}

As shown in Fig. 3a, a significant decrease in absorbance was observed when TeNWs were incubated with different
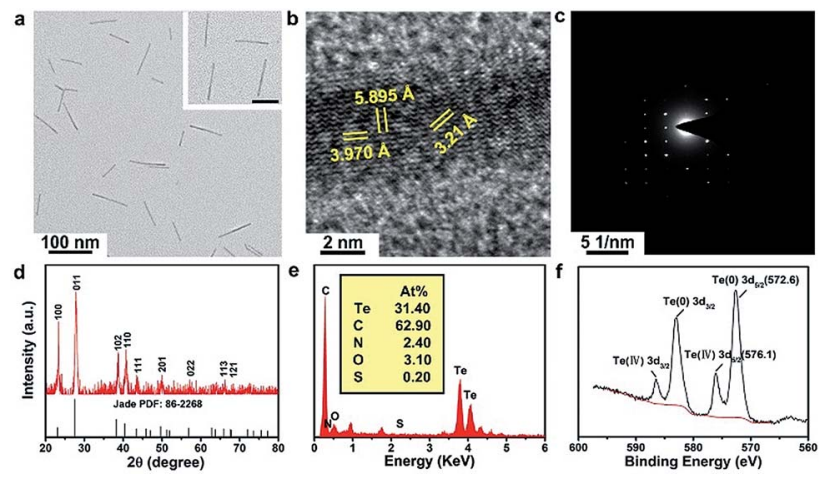

Fig. 2 Structural characterization of TeNWs. (a) TEM, scale bar in the inset picture is $50 \mathrm{~nm}$, (b) HRTEM, scale bar: $50 \mathrm{~nm}$, (c) electron diffraction pattern of TeNWs, (d) XRD patterns, (e) EDXS analysis spectrum of TeNWs, and (f) Te $3 d$ binding energy of TeNWs. 

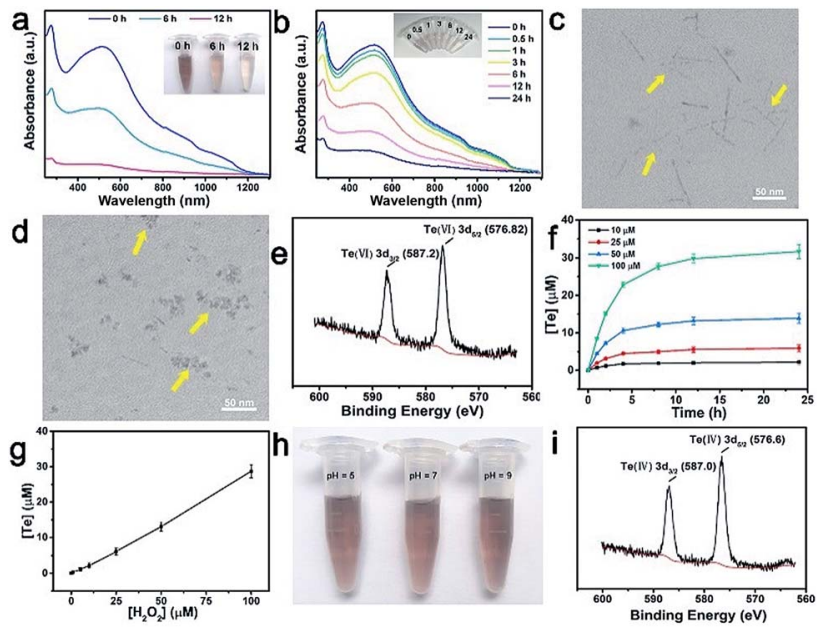

Fig. 3 (a) UV/vis absorption spectra of TeNWs treated with $\mathrm{H}_{2} \mathrm{O}_{2}$ (the inset shows the solution corresponding to the absorption curve). (b) UV/vis absorption spectra and photo (inset) of TeNWs $(40 \mu \mathrm{M})$ reacted with hydrogen peroxide $(100 \mu \mathrm{M})$ for different times. The TEM image of TeNWs after treating with $\mathrm{H}_{2} \mathrm{O}_{2}$ for $3 \mathrm{~h}$ (c) and $12 \mathrm{~h}$ (d). (e) Te 3d Binding energy of $\mathrm{TeO}_{6}{ }^{6-}$. (f) The curves of increased tellurium ion concentration released from TeNWs $(40 \mu \mathrm{M})$ which reacted with different concentrations of hydrogen peroxide $(10,25,50$ and $100 \mu \mathrm{M})$ over time. (g) The tellurium ion concentration released from TeNWs after reacting with different concentrations of $\mathrm{H}_{2} \mathrm{O}_{2}$ for 24 hours. (h) TeNWs incubated in different $\mathrm{pH}$ solutions for 7 days. (i) Te $3 \mathrm{~d}$ binding energy of tellurium in solution where TeNWs react step-by-step with $\mathrm{H}_{2} \mathrm{O}_{2}$ and GSH.

concentrations of $\mathrm{H}_{2} \mathrm{O}_{2}$ for $24 \mathrm{~h}$ in aqueous solution. The absorption intensity also decreased with reaction time until one of the reactants was completely exhausted (Fig. 3b). At the same time, the color of the TeNW solution became lighter due to the formation of colorless telluric acid. The morphology of TeNWs collapsed after the reaction with $\mathrm{H}_{2} \mathrm{O}_{2}$ for $3 \mathrm{~h}$ (Fig. 3c) and changed to small fragments after $12 \mathrm{~h}$ of reaction (Fig. 3d). To investigate the reaction between $\mathrm{Te}$ and $\mathrm{H}_{2} \mathrm{O}_{2}$, the oxidation state of Te in the product was studied first. As shown in Fig. 3e, the oxidation state of Te in TeNWs after treatment with $\mathrm{H}_{2} \mathrm{O}_{2}$ was +VI. Further, as can be seen from Fig. $3 \mathrm{f}$ and g, it takes 3 equivalents of hydrogen peroxide to consume one mole of $\left[\mathrm{TeO}_{6}{ }^{6-}\right]$. Based on the above results, the reaction process can be assumed to follow eqn (5):

$$
\mathrm{Te}+3 \mathrm{H}_{2} \mathrm{O}_{2} \rightarrow 6 \mathrm{H}_{6} \mathrm{TeO}_{6}
$$

By calculating the kinetic parameters, the reaction rate constant $k$ is about $2.4 \times 10^{-5} \mathrm{~s}^{-1}$, and it can be known that the reaction equation is first-order, which means that the reaction rate of TeNWs and $\mathrm{H}_{2} \mathrm{O}_{2}$ is positively correlated with the concentration of $\mathrm{H}_{2} \mathrm{O}_{2}$, resulting in the selective killing behaviour of TeNWs.

Because the concentration of $\mathrm{H}_{2} \mathrm{O}_{2}$ in normal cells can be as low as $\sim 20 \mathrm{nM}, \mathrm{H}_{2} \mathrm{O}_{2}(100 \mathrm{nM})$ was reacted with TeNWs for $24 \mathrm{~h}$, and the absorption curve of the solution was substantially unchanged, which inferred that the $\mathrm{H}_{2} \mathrm{O}_{2}$ concentration in normal cells does not cause degradation of TeNWs (Fig. S8†). Due to the acidic environment of tumor cells, the stability of TeNWs was further tested in different $\mathrm{pH}$ solutions. The absence of significant fading of TeNWs after mixing with solutions of different $\mathrm{pH}$ for 7 days indicates that TeNWs are stable in a $\mathrm{pH}$ range of 5-9 (Fig. $3 \mathrm{~h}$ ). Meanwhile, the $\mathrm{pH}$ value in the human body has little effect on the reaction of TeNWs and $\mathrm{H}_{2} \mathrm{O}_{2}$ (Fig. S9†). Interestingly, we found that TeNWs can react with $\mathrm{H}_{2} \mathrm{O}_{2}$ and GSH sequentially, because the product of the reaction between Te and $\mathrm{H}_{2} \mathrm{O}_{2}$ will continue to react with GSH, whose valence was changed from +VI to + IV (Fig. 3i).

\section{In vitro cancer cell therapy using TeNWs}

Furthermore, the toxic effect of the product of TeNWs and $\mathrm{H}_{2} \mathrm{O}_{2}$ was studied. Since $\mathrm{H}_{2} \mathrm{O}_{2}$ can serve as a target molecule for a tumor-specific response, the selective killing effect of TeNWs on cancer and normal cells was further tested. Three types of cancer cells lines, MCF-7 (human breast-cancer cells), HeLa (human cervical cancer cells), A549 (human lung cancer cells), and two types of normal cells, L02 (normal human liver cells) and HSF (human skin fibroblasts cells) cell lines, were incubated with TeNWs for $24 \mathrm{~h}$. TeNWs showed high toxicity to cancer cells and no killing effect on normal cells, especially MCF-7 cells (Fig. 4a). In addition, the concentration of $\mathrm{H}_{2} \mathrm{O}_{2}$ in these cells was detected using a hydrogen peroxide assay kit (Beyotime, S0038), which was significantly decreased after coincubation with TeNWs for $6 \mathrm{~h}$, while that in normal cells only decreased slightly (Fig. 4b). We further stained the live and dead cells with calcein-AM and propidium iodide (PI), respectively, to further confirm the therapeutic capacity of TeNWs (Fig. 4c, $\mathrm{d}$ and $\mathrm{S} 10 \dagger)$. Almost all cells in the control group are green, indicating their vitality. However, cells treated with TeNWs (40 $\mu \mathrm{g} \mathrm{mL}^{-1}$ ) had died, verifying the cancer cell killing effect of TeNWs. This selective killing effect of TeNWs on cancer cells is

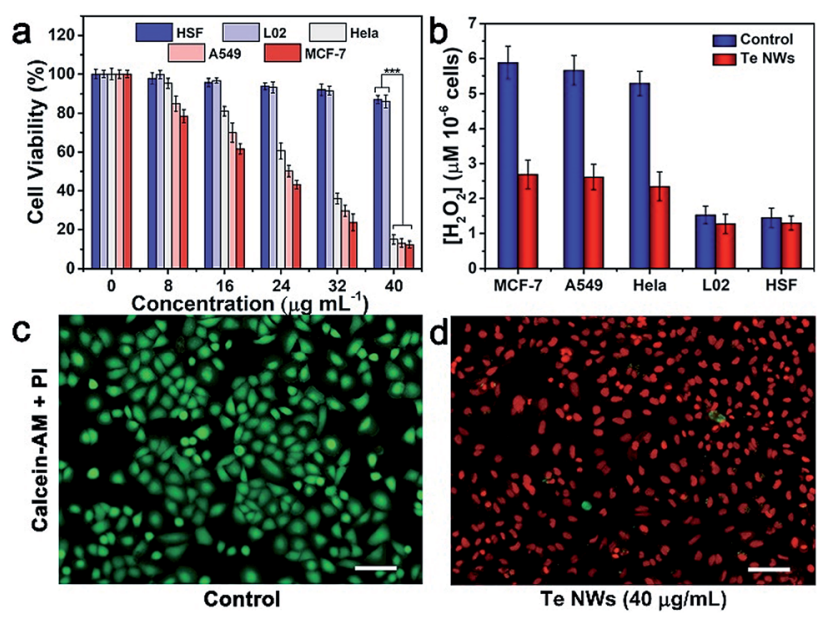

Fig. 4 (a) Anticancer activity of TeNWs against cancer and normal cell lines. $* P<0.05$, $* * P<0.01$, and $* * * P<0.001$. (b) Changes in the intracellular $\mathrm{H}_{2} \mathrm{O}_{2}$ concentration after co-incubation of different cells with TeNWs. Calcein and PI stained HeLa cells treated with PBS (c) or TeNWs (d). Scale bar: $100 \mu \mathrm{m}$. 
mediated by the high concentration of $\mathrm{H}_{2} \mathrm{O}_{2}$ in cancer cells. At the same time, rod shaped TeNWs exhibited a relatively higher cell uptake efficacy, because the sharp effect is favorable for cell uptake behavior.

To further investigate the underlying mechanism of the TeNW efficacy against cancer cells, the ROS fluorescent probe DCFH-DA was used to detect the concentration of $\mathrm{H}_{2} \mathrm{O}_{2}$ in cells. The fluorescence signal intensity of DCF-DA is $\mathrm{H}_{2} \mathrm{O}_{2}$-dependent. Under identical test conditions, the control group of MCF-7 showed a stronger fluorescence signal than MCF-7 cells treated with TeNWs, while the fluorescence signal of L02 cells treated with or without TeNWs was negligible (Fig. 5a). This is consistent with other experimental results shown in Fig. $4 \mathrm{~b}$.

To explore the mechanism underlying cell death caused by TeNWs, cells were stained using an Annexin V-FITC apoptosis detection kit. Apoptotic cells showed green fluorescence of Annexin V-FITC, which may be stained with red fluorescence of propidium iodide in some content. Meanwhile, living cells do not carry any fluorescence. As shown in Fig. 5b, with increasing TeNW dosage, the proportion of viable apoptotic cells in the flow data increased from $0.158 \%$ to $50 \%$, while the proportion of surviving cells decreased from $97.8 \%$ to $0.985 \%$. The nontoxic nature of TeNWs for normal cells was demonstrated by
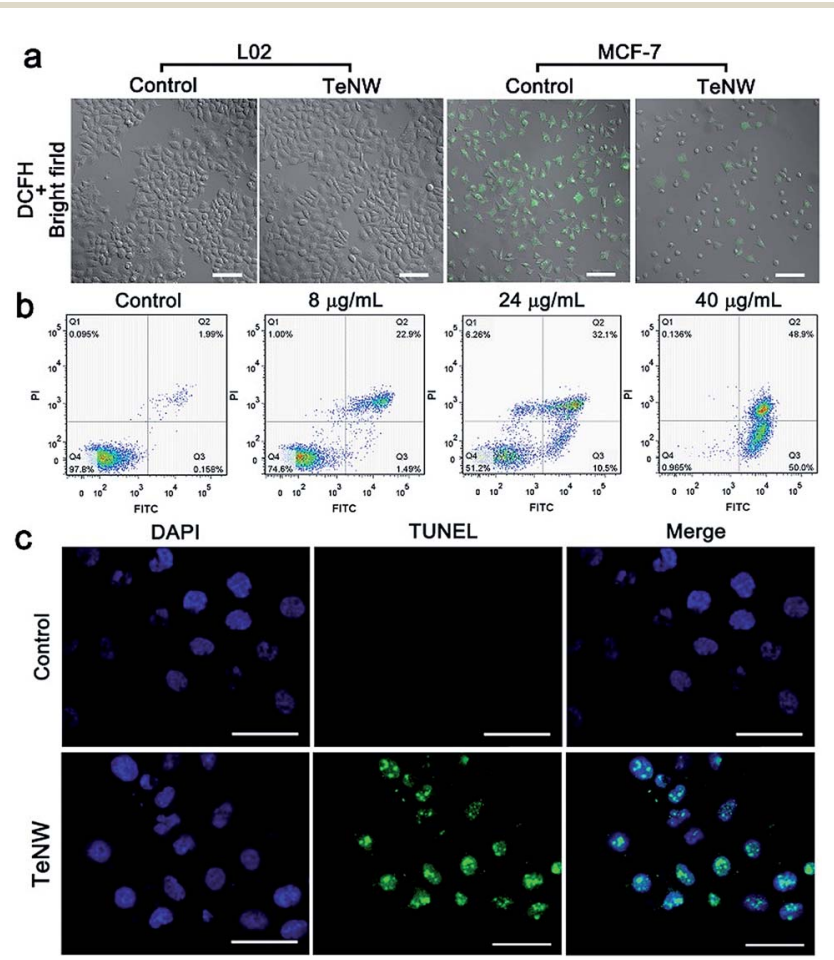

TUNEL

Merge
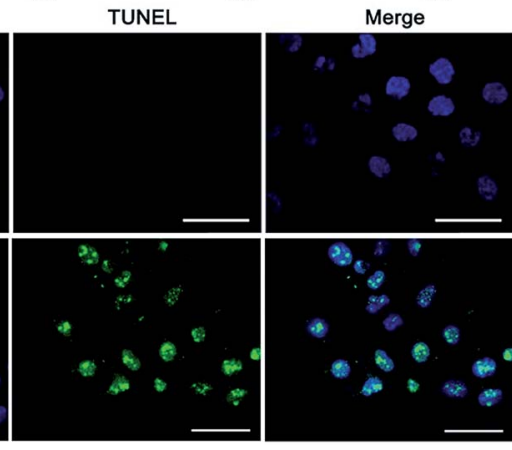

Fig. 5 (a) Confocal fluorescence microscope images of L02 cells and MCF-7 cells after different treatments for $6 \mathrm{~h}$. Scale bar: $100 \mu \mathrm{m}$. (b) Contour diagram of FITC-Annexin V/PI flow cytometry of MCF-7 cells after treatment with TeNWs for 24 h (Q1 represents necrotic cells; Q2 contains non-viable late apoptosis/necrosis cells, which are positive for FITC-Annexin V binding and PI uptake; Q3 represents apoptotic cells, FITC-Annexin $V$ positive, and PI negative; $Q 4$ shows viable cells without PI and negative for FITC-Annexin $V$ binding). (c) DNA fragmentation and nuclear condensation (scale bar: $50 \mu \mathrm{m}$ ) in MCF-7 cells treated with TeNWs $\left(40 \mu \mathrm{g} \mathrm{mL}^{-1}\right)$ for $24 \mathrm{~h}$. double staining normal cells L02 with Hoechst 33342/PI and detecting the fluorescence signal by flow cytometry, in which only $9.45 \%$ cell apoptosis was detected (Fig. S11†). DNA fragments stained with FITC due to cleavage were distributed in the DAPI-stained nucleus of MCF-7 cells treated with TeNWs; in contrast, the control group did not have any DNA fragments stained green (Fig. 5c). This result clearly indicates that TeNWs would cause cell apoptosis via cleavage of DNA within the nucleus after incubation with TeNWs.

In addition to $\mathrm{H}_{2} \mathrm{O}_{2}$, the GSH level is also high in cancer cells. It has been reported that GSH is the target of Te toxicity. ${ }^{39}$ Therefore, this study hypothesized that the product $\mathrm{TeO}_{6}{ }^{6-}$ can react next with GSH in cancer cells. The possible reaction mechanism is as follows (eqn (6)):

$$
n \mathrm{GSH}+\mathrm{TeO}_{6}{ }^{6-} \rightarrow \mathrm{GS}^{-} \mathrm{Te}-\mathrm{GS}+\mathrm{GSSG}
$$

After the cancer cells were treated with TeNWs, GSH and GSSG test kits (S0053, Beyotime) were employed to detect the concentration of GSH and GSSG in cells. Telluric acid can react with GSH and generate GSSG (Fig. S12a $\dagger$ ), and the ratio of intracellular GSSG/GSH significantly increased after MCF-7 and HeLa cells were incubated with TeNWs $\left(24 \mu \mathrm{g} \mathrm{mL}{ }^{-1}\right)$ for $24 \mathrm{~h}$ (Fig. S12b $\dagger$ ). The decrease of GSH is very beneficial for the improvement of the cancer cell therapeutic effect caused by ROS, because GSH typically consumes ROS, thus obstructing the elimination of malignant free radicals in a timely and effective manner. ${ }^{40}$ As shown in Fig. S13, $\dagger$ after 24 hours of coincubation with TeNWs, the intracellular ROS level of MCF-7 cells was greatly increased. We also investigated whether telluric acid or ROS was responsible for DNA damage. By inhibiting GSH production with butyl methionine-sulfoximine (BSO), the killing effect of TeNWs on cells was weakened, which means that telluric acid also lead to apoptosis but not just because of the increase in ROS; moreover, the main source of cell apoptosis is telluric acid (Fig. S14 and S15 $\dagger$ ). As reported in a number of studies, malignant free radicals can act as a dangerous signal to activate the maturation of immune cells. ${ }^{\mathbf{4 1}}$ To investigate the source of cytotoxicity caused by TeNWs, we performed proteomic analysis on MCF-7 cells and tumor tissues treated with TeNWs for $24 \mathrm{~h}$ (Fig. S16†). Gene ontology (GO) is a standardized gene function classification system. We perform GO enrichment analysis on selected differentially expressed proteins and show the top 10 GO entries in Fig. S16a and b. $\dagger$ As shown in the figure, there are significant differential expressions of autophagy and neutrophil-associated proteins in the bioprocess group, meanwhile, a large number of vesicle membranes and the lysosomal membrane-associated proteins are significantly differentially expressed in the cell component group. Fig. S16c† shows a heatmap of relevant significant proteins. It can be seen that CSNK2B, RRAGC, SUPT5H, TOMM40, GNAI3, SQSTM1, TOMM22, and other autophagyrelated genes are up-regulated in cells treated with TeNWs. The expression of MAPK14 which inhibits autophagy is downregulated, and the expression of neutrophil degranulation proteins PSAP, STOM, DNAJC3, CPNE1, CAT, and HP is significantly up-regulated in both groups. In the tumor, PSMB7, 
RAP2A, MIF and other neutrophil degranulation-related proteins were up-regulated too. Combined with the results of TUNEL and Annexin-V/FITC analysis, it can be speculated that TeNWs can cause caspase-independent autophagic death and apoptosis, and immune responses. Thus, the mechanism underlying the efficacy of TeNWs as a nano-prodrug against cancer cells is a variety of pathways.

\section{In vivo biosafety, imaging and selective tumor therapy of TeNWs}

Encouraged by the cell-killing effect of TeNWs, its in vivo behavior was investigated. A hemolysis test, a toxicologically central factor, was employed to determine whether TeNWs can be used as a theranostic reagent in vivo. TeNWs at a concentration of $50 \mu \mathrm{g} \mathrm{mL}^{-1}$ did not cause swelling, rupture, or coagulation of red blood cells (RBCs) during $3 \mathrm{~h}$ of blending. The hemolysis rate did not exceed $5 \%$ even at a TeNW level of $50 \mu \mathrm{g}$ $\mathrm{mL}^{-1}$, indicating that TeNWs have good blood compatibility and are suitable for in vivo diagnosis and treatment (Fig. 6a).

To trace the in vivo behavior of TeNWs, ${ }^{\mathbf{4 2}-44}$ photoacoustic (PA) imaging was employed to study its increase with increasing TeNW concentration (Fig. $6 \mathrm{~b}$ and $\mathrm{S} 17 \mathrm{a} \dagger$ ). At $24 \mathrm{~h}$ post-injection of TeNWs, the PA signal in the tumor area was significantly enhanced (Fig. 6c), indicating that TeNWs were accumulated in the tumor site. The PA signal intensity in tumors treated with TeNWs was $\sim 10$ times higher than that of PBS treated tumors (Fig. S17b $\dagger$ ). Efficient accumulation of TeNWs in the tumor region was further verified by ex vivo biodistribution data at
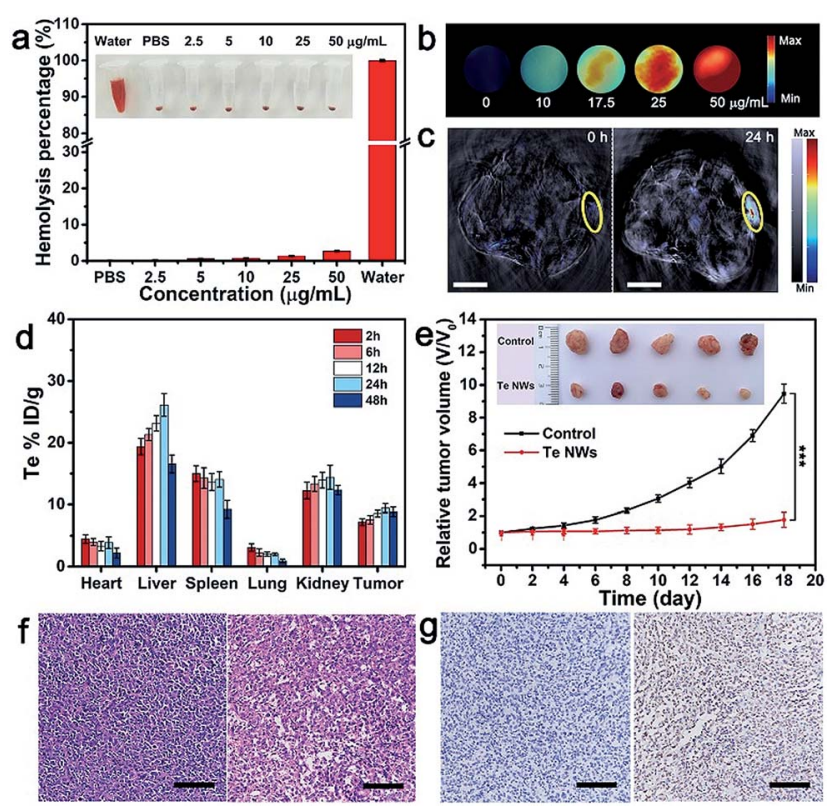

Fig. 6 (a) The percentages of hemolysis in response to different concentrations of TeNWs. Inset: photograph of Eppendorf-tubes containing the supernatant from RBCs exposed to different concentrations of TeNWs. (b) PA images of TeNW solutions. (c) PA images of the tumor. (d) Tumor growth curves of tumor-bearing mice (inset: the photographs of the tumor in each group). (e) Biodistribution of Te in main organs and tumors. (f) H\&E-stained tumor slices. (g) TUNEL staining of pathological changes in tumor tissues. different time points obtained by measuring the Te content of the major organs via inductively coupled plasma mass spectrometry (Fig. 6d).

Two groups of MCF-7 tumor-bearing female Balb/c nude mice were intravenously injected three times every other day with PBS and TeNWs, respectively. The tumor growth in the treatment group was significantly suppressed (Fig. 6e). In sharp contrast, tumors of the control group exhibited rapid growth. There was no significant weight loss in both groups during the experiment (Fig. S18 $\dagger$ ). As shown in Fig. 6f, compared to the control group, the mice treated with TeNWs presented significant nuclear condensation and fragmentation in HE images. The TUNEL staining data showed that the tumor cell apoptosis rate in the treatment group was as high as $85.61 \%$ (Fig. 6g). Due to the dissociation and small size of BSA-dextran coated TeNWs, it was removed from the body after treatment (Fig. 6d and $\mathrm{S} 19 \dagger)$. The mice treated with TeNWs survived for over 40 days (Fig. S20†).

To study the biocompatibility of TeNWs in vivo, the main blood biochemical parameters of mice treated with TeNWs were measured at different post-injection time points. These parameters included albumin (ALB), alanine aminotransferase (ALT), aspartate amino transferase (AST), blood urea nitrogen (BUN), total bilirubin (TBL), and total protein (TP). No significant variations of these index values were observed between the experimental group and the control group (Fig. S21a $\dagger$ ). These results showed that mice treated with TeNWs showed no significant inflammation and infection. In addition, the normality of ALT and AST values (indicators of liver-related function) showed that TeNWs have no significant hepatic toxicity. Moreover, TeNWs also had no significant toxic side effects on the major organs based on H\&E imaging (Fig. S21b $\dagger$ ).

\section{Conclusions}

In conclusion, this study successfully developed TeNWs as an intelligent inorganic nanoprodrug that reacts with $\mathrm{H}_{2} \mathrm{O}_{2}$ to kill cancer cells with high efficiency. TeNWs further interacted with GSH via a metal-reducing reaction that decreased the intracellular GSH levels. The greatly enhanced therapeutic effect could be attributed to the combination of $\mathrm{H}_{2} \mathrm{O}_{2}$, which triggered the generation of ROS by TeNWs and decreased GSH levels. Moreover, TeNWs had a high tumor accumulation efficiency and cancer therapeutic efficacy through caspase-independent autophagic death and apoptosis and even cause an immune response. Following therapy, TeNWs were completely cleared from the body due to $\mathrm{H}_{2} \mathrm{O}_{2}$-triggered disassociation of TeNWs. TeNWs also showed a highly targeted cancer therapy effect, and did not kill normal cells due to their lower level of $\mathrm{H}_{2} \mathrm{O}_{2}$. Therefore, TeNWs are a new selective and $\mathrm{H}_{2} \mathrm{O}_{2}$-responsive cancer therapy nano-prodrug.

\section{Experimental methods}

\section{Chemicals}

Tellurium powder (99.99\%), sodium borohydride and BSA were purchased from Sigma-Aldrich. Dextran $(40 \mathrm{kDa})$ was purchased 
from Sinopharm Chemical Reagent Co. Ltd. Calcein-AM and propidium iodide (PI) were supplied by Beyotime Biotechnology (Beijing, China). All chemicals were used as received without further purification. Ultrapure water was obtained from a Milli$\mathrm{Q}$ water purification system (18.2 $\mathrm{M} \Omega$ resistivity, Millipore).

\section{Synthesis of BSA-dextran conjugates}

BSA $(2 \%, w / v)$ and dextran $(4 \%, w / v)$ were first dissolved together in ultrapure water. After full hydration, the solution $\mathrm{pH}$ value was adjusted to 7.0. The sample was lyophilized and the powder was incubated in a desiccator over a saturated $\mathrm{KBr}$ solution (79\% relative humidity) for $24 \mathrm{~h}$ at $60{ }^{\circ} \mathrm{C}$ to produce dextran glycosylated BSA. After conjugation, all samples were ground and collected, and then stored at $-20{ }^{\circ} \mathrm{C}$ for further use.

\section{Synthesis of tellurium nanowires (TeNWs)}

Typically, $0.0300 \mathrm{~g}(0.234 \mathrm{mmol})$ of the tellurium powder was immersed and stirred in $20 \mathrm{~mL}$ of water in a $250 \mathrm{~mL}$ three necked round bottom flask that was filled with an inert gas. Then the solution was heated to $90{ }^{\circ} \mathrm{C} .50 \mathrm{mg}(1.3 \mathrm{mmol}) \mathrm{NaBH}_{4}$ was then added to the flask and the mixture was again purged with inert gas. When the solution color turned purple, it was diluted with $100 \mathrm{~mL}$ of $90{ }^{\circ} \mathrm{C}$ deionized water with $250 \mathrm{mg}$ of BSA-dextran (equivalent BSA only or dextran only). The mixed solution was stirred until the temperature returned to $90{ }^{\circ} \mathrm{C}$.

After the removal of byproducts by centrifugation $(27000$ rpm, $20 \mathrm{~min}$ ), the TeNW products were further collected by recentrifugation (35 $000 \mathrm{rpm}, 20 \mathrm{~min}$ ), followed by washing with deionized water several times. The as-prepared TeNWs were dispersed in deionized water and stored at $4{ }^{\circ} \mathrm{C}$ for further use.

\section{Cytotoxicity assay}

Cell viability was measured with a CCK-8 according to the manufacturer's protocol. For the cytotoxicity assay, MCF-7 (human breast-cancer cells), HeLa (human cervical cancer cells), A549 (human lung cancer cells), L02 (normal human liver cells) and HSF (human skin fibroblasts) cell lines were first cultured in 96-well plates $\left(100 \mu \mathrm{L}, 1 \times 10^{4}\right.$ cells per well $)$ at $37^{\circ} \mathrm{C}$ in a humidified atmosphere with $5 \% \mathrm{CO}_{2}$ for $24 \mathrm{~h}$. After incubation for another $24 \mathrm{~h}$, the culture medium was replaced with $100 \mu \mathrm{L}$ of the corresponding free cell culture medium with $10 \%$ FBS containing $20 \mu \mathrm{L}$ of TeNWs at different doses, resulting in a final TeNW concentration of $0,8,16,24,32$ and $40 \mu \mathrm{g} \mathrm{mL}^{-1}$. After the removal of the culture medium, $10 \mu \mathrm{L}$ of CCK- 8 solution mixed with $90 \mu \mathrm{L}$ of culture medium was added to each cell well which was washed with PBS twice. The cells were further incubated until the $\mathrm{OD}_{450}$ value of the control group equals about one. The $\mathrm{OD}_{450}$ value (Abs.) of each well was measured using a SH-1000 Lab microplate reader immediately and the cell viability was calculated from the $\mathrm{OD}_{450}$ value of the experimental group by subtracting that of the blank group.

\section{Hydrogen peroxide consumption}

$400 \mu \mathrm{L}$ aqueous solutions containing $40 \mu \mathrm{M}$ TeNWs and different concentrations of $\mathrm{H}_{2} \mathrm{O}_{2}(0,1,5,10,25,50$ and $100 \mu \mathrm{g}$
$\left.\mathrm{mL}^{-1}\right)$ were prepared. After incubation for a pre-determined time $(0,1,2,4,8,12$ and $24 \mathrm{~h})$, the solution was centrifuged at $40000 \mathrm{rpm}$ to measure the concentration of the released tellurium ions through ICP-MS.

\section{$\mathrm{H}_{2} \mathrm{O}_{2}$ consumption in cell lines}

MCF-7, HeLa, A549, L02, and HSF cell lines were first cultured in 6-well plates $\left(1 \mathrm{~mL}, 1 \times 10^{6}\right.$ cells per well) at $37{ }^{\circ} \mathrm{C}$ in a humidified atmosphere with $5 \% \mathrm{CO}_{2}$ for $12 \mathrm{~h}$. After incubation for another $4 \mathrm{~h}$, the culture medium was replaced with 1 $\mathrm{mL}$ of culture medium containing $24 \mu \mathrm{g} \mathrm{mL}{ }^{-1}$ of TeNWs. After the removal of the culture medium, the intracellular $\mathrm{H}_{2} \mathrm{O}_{2}$ concentration was measured using a $\mathrm{H}_{2} \mathrm{O}_{2}$ detection kit (Beyotime, S0038) according to the manufacturer's protocol.

\section{Intracellular $\mathrm{H}_{2} \mathrm{O}_{2}$ detection}

DCFH-DA was used as a probe to detect intracellular $\mathrm{H}_{2} \mathrm{O}_{2}$ generation. First, MCF-7 cells and HSF cells were incubated with $24 \mu \mathrm{g} \mathrm{mL}{ }^{-1}$ of TeNWs at $37^{\circ} \mathrm{C}$ for $12 \mathrm{~h}$ in 96-well plates. Then, $10 \mu \mathrm{M}$ DCFH-DA was added to the cell culture medium and then incubated for $30 \mathrm{~min}$. Finally, the well plates were imaged using a Nikon A1 confocal laser scanning microscope.

\section{Quantification of cell apoptosis}

To analyze quantitatively the apoptosis of MCF-7 cells treated with TeNWs, Annexin V-FITC-labeled cells were quantified and considered to be apoptotic cells. Samples were prepared as for the assessment of apoptosis-related genes $(n=3$ for each group). Briefly, after $24 \mathrm{~h}$ of treatment, the samples were washed twice with PBS and stained using an Annexin V-FITC apoptosis detection kit (Beyotime, China) according to the manufacturer's protocol. Annexin V-FITC and PI-labeled cells were identified using flow cytometry (BD FACSVerse; BD Biosciences, USA), and the data were processed and analyzed using FlowJo software.

\section{Hemolysis assay}

In order to determine whether the red blood cells (RBCs) would be damaged by TeNWs during experiments in vivo, a hemolysis assay was carried out. RBCs were isolated from the serum by centrifugation. The RBCs were washed with PBS until the supernatant was colorless and transparent, and the purified blood was diluted to $1 / 10$ of its volume with PBS to get $2 \%$ of the blood cells. $100 \mu \mathrm{L}$ of the cell suspension were treated with different concentrations of TeNWs $(5,10,15,20,25$ and $50 \mu \mathrm{g} \mathrm{mL}{ }^{-1}$ ) and incubated on a shaking table at $37{ }^{\circ} \mathrm{C}$ for 3 hours. The RBCs treated with $900 \mu \mathrm{L}$ of PBS and deionized water were regarded as negative and positive controls, respectively. After incubation, samples were centrifuged and aspirated to a 96-well plate to measure the absorbance at 541 $\mathrm{nm}$ with a microplate reader. The percent hemolysis of RBCs was calculated as follows: percent hemolysis $=\left[\left(A_{\text {sample }}-\right.\right.$ $\left.\left.A_{\text {negative control }}\right) /\left(A_{\text {positive control }}-A_{\text {negative control }}\right)\right] \times 100 \%$. 


\section{In vivo toxicity assay}

All animal experiments were performed in compliance with the Guide for the Care and Use of Laboratory Animals (Ministry of Science and Technology of China, 2006) and approved by the Institutional Animal Care and Use Committee of Fujian Medical University. BALB/c nude mice (8 weeks old) were obtained from Shanghai SLAC laboratory Animal Co., Ltd. SBF-level mice were divided into two groups: (1) the control group and (2) mice intravenously administered with TeNWs. The TeNW dose for the treatment group was $0.25 \mathrm{mg} \mathrm{kg}{ }^{-1}$. The histological and blood biochemical indexes were collected at various time intervals after intravenous administration. For hematology and biochemical analysis, blood was collected from mice and separated by centrifugation into cellular and serum fractions. The hematology data and serum biochemistry data were recorded on a MINDRAY BC-5500 automated hematology analyzer (MINDRAY, China) and a HITACHI 7020 automatic biochemical analyzer (HITACHI, Japan), respectively. For histology analysis, mice were sacrificed and major organs from these mice were harvested, dipped in $10 \%$ neutral buffered formalin, then embedded in paraffin, and stained with H\&E and TUNEL. The pathology was examined using a digital microscope. All the statistics were based on standard deviations of 5 mice per group.

\section{In vivo PA imaging}

Different concentrations of TeNWs $(5,10,17.5,25$, and $50 \mu \mathrm{g}$ $\mathrm{mL}^{-1}$ ) dissolved in purified water were loaded into agar gel cylinders and used for in vitro PA imaging signal detection. For in vivo PA imaging, the scanning was first performed before TeNW injection as controls. Next, the MCF-7-tumor-bearing mice were intravenously administered with TeNWs $(0.25 \mathrm{mg}$ $\mathrm{kg}^{-1}$ ). All of the PA images were obtained using an Invision 128 MSOT system (iThera Medical, Germany) to collect the optoacoustic signals (laser wavelengths: $680-980 \mathrm{~nm}$; the main experimental parameters were $2 \mathrm{~mm}$ wavelength for each slice, wavelength $680 \mathrm{~nm}$ ). A water heating system was used to maintain the body temperature of mice at $\sim 37^{\circ} \mathrm{C}$ during the scanning processes. The tumor region of the mice was scanned with a VisualSonic Vevo 2100 LAZR system equipped with a 40 $\mathrm{MHz}$, 256-element linear array transducer at different time points.

\section{Biodistribution and metabolism studies}

The female Balb/c nude mice ( $\sim 20 \mathrm{~g})$ were obtained from Shanghai SLAC laboratory Animal Co., Ltd. To develop the tumor model, tumor-bearing mice were prepared by subcutaneously injecting a suspension of $1 \times 10^{7}$ MCF-7 cells in PBS $(100 \mu \mathrm{L})$ into the back of the hind leg. After the tumor volume of nude mice exceeds $1000 \mathrm{~cm}^{3}$, they will be sacrificed for humanitarianism.

The biodistribution of TeNWs in tumors and other organs was evaluated in MCF-7 tumor-bearing mice. The MCF-7-tumorbearing mice were given intravenous TeNWs $\left(0.25 \mathrm{mg} \mathrm{kg}^{-1}\right)$ in PBS. Mice were dissected at preset time intervals $(2,6,12,24$, and 48 hours and 7 days). The dissected organs were weighed, homogenized and treated with a strong acid. TeNW distribution in different tissues was calculated as the percentage of injected dose per gram of tissue.

\section{Conflicts of interest}

There are no conflicts to declare.

\section{Acknowledgements}

This research was supported by the National Natural Science Foundation of China (No. U1505221, 21635002, and 21874024), the Program for Changjiang Scholars and Innovative Research Team in University (No. IRT15R11).

\section{Notes and references}

1 L. S. Lin, J. Song, L. Song, K. Ke, Y. Liu, Z. Zhou, Z. Shen, J. Li, Z. Yang, W. Tang, G. Niu, H. H. Yang and X. Chen, Angew. Chem., Int. Ed. Engl., 2018, 57, 4902-4906.

2 Y. D. Lee, C. K. Lim, A. Singh, J. Koh, J. Kim, I. C. Kwon and S. Kim, ACS Nano, 2012, 6, 6759-6766.

3 G. Yang, L. Xu, Y. Chao, J. Xu, X. Sun, Y. Wu, R. Peng and Z. Liu, Nat. Commun., 2017, 8, 902.

4 Z. Yang, W. Fan, W. Tang, Z. Shen, Y. Dai, J. Song, Z. Wang, Y. Liu, L. Lin, L. Shan, Y. Liu, O. Jacobson, P. Rong, W. Wang and X. Chen, Angew. Chem., Int. Ed. Engl., 2018, 57, 1410114105.

5 L. Chan, P. Gao, W. Zhou, C. Mei, Y. Huang, X. F. Yu, P. K. Chu and T. Chen, ACS Nano, 2018, 12(12), 12401-12415.

6 X. R. Song, S. H. Li, J. Dai, L. Song, G. Huang, R. Lin, J. Li, G. Liu and H. H. Yang, Small, 2017, 13, 1603997.

7 T. Zhao, G. Huang, Y. Li, S. Yang, S. Ramezani, Z. Lin, Y. Wang, X. Ma, Z. Zeng, M. Luo, E. de Boer, X. J. Xie, J. Thibodeaux, R. A. Brekken, X. Sun, B. D. Sumer and J. Gao, Nat. Biomed. Eng., 2016, 1, 0006.

8 D. Ni, D. Jiang, H. F. Valdovinos, E. B. Ehlerding, B. Yu, T. E. Barnhart, P. Huang and W. Cai, Nano Lett., 2017, 17, 3282-3289.

9 W. W. Zhu, Z. L. Dong, T. T. Fu, J. J. Liu, Q. Chen, Y. G. Li, R. Zhu, L. G. Xu and Z. Liu, Adv. Funct. Mater., 2016, 26, 5490-5498.

10 M. Song, T. Liu, C. Shi, X. Zhang and X. Chen, ACS Nano, 2016, 10, 633-647.

11 J. Chen, H. Luo, Y. Liu, W. Zhang, H. Li, T. Luo, K. Zhang, Y. Zhao and J. Liu, ACS Nano, 2017, 11, 12849-12862.

12 D. Mao, W. B. Wu, S. L. Ji, C. Chen, F. Hu, D. L. Kong, D. Ding and B. Liu, Chem, 2017, 3, 991-1007.

13 B. Halliwell, M. V. Clement and L. H. Long, FEBS Lett., 2000, 486, 10-13.

14 L. Yu, Y. Chen and H. Chen, Chin. Chem. Lett., 2017, 28, 1841-1850.

15 M. Lopez-Lazaro, Cancer Lett., 2007, 252, 1-8.

16 S. T. kunP, K. Okamoto, J. Yodoib and H. Hiai, FEBS Lett., 1995, 358, 1-3. 
17 P. Rungtabnapa, U. Nimmannit, H. Halim, Y. Rojanasakul and P. Chanvorachote, Am. J. Physiol., 2011, 300, C235-C245.

18 K. Kono, F. Salazar-Onfray, M. Petersson, J. Hansson, G. Masucci, K. Wasserman, T. Nakazawa, P. Anderson and R. Kiessling, Eur. J. Immunol., 1996, 26, 1308-1313.

19 L. Alili, M. Sack, C. von Montfort, S. Giri, S. Das, K. S. Carroll, K. Zanger, S. Seal and P. Brenneisen, Antioxid. Redox Signaling, 2013, 19, 765-778.

20 L. Chen and J. Song, Adv. Funct. Mater., 2017, 27, 1702695.

21 Q. Cui, J. Q. Wang, Y. G. Assaraf, L. Ren, P. Gupta, L. Wei, C. R. Ashby Jr, D. H. Yang and Z. S. Chen, Drug Resist. Updates, 2018, 41, 1-25.

22 Y. Wang, W. Yin, W. Ke, W. Chen, C. He and Z. Ge, Biomacromolecules, 2018, 19, 1990-1998.

23 Z. Tang, H. Zhang, Y. Liu, D. Ni, H. Zhang, J. Zhang, Z. Yao, M. He, J. Shi and W. Bu, Adv. Mater., 2017, 29, 1701683.

24 L. K. Abdelmohsen, M. Nijemeisland, G. M. Pawar, G. J. Janssen, R. J. Nolte, J. C. van Hest and D. A. Wilson, ACS Nano, 2016, 10, 2652-2660.

25 S. Giri, A. Karakoti, R. P. Graham, J. L. Maguire, C. M. Reilly, S. Seal, R. Rattan and V. Shridhar, PLoS One, 2013, 8, e54578.

26 M. Sack, L. Alili, E. Karaman, S. Das, A. Gupta, S. Seal and P. Brenneisen, Mol. Cancer Ther., 2014, 13, 1740-1749.

27 Y. Peng, Z. Zhao, T. Liu, X. Li, X. Hu, X. Wei, X. Zhang and W. Tan, Angew. Chem., Int. Ed. Engl., 2017, 56, 10845-10849.

28 Z. He, Y. Yang, J. W. Liu and S. H. Yu, Chem. Soc. Rev., 2017, 46, 2732-2753.

29 A. P. Fernandes and V. Gandin, Biochim. Biophys. Acta, 2015, 1850, 1642-1660.

30 Y. Chang, L. He, Z. Li, L. Zeng, Z. Song, P. Li, L. Chan, Y. You, X. F. Yu, P. K. Chu and T. Chen, ACS Nano, 2017, 11, 48484858.
31 F. Li, T. Li, C. Sun, J. Xia, Y. Jiao and H. Xu, Angew. Chem., Int. Ed. Engl., 2017, 56, 9910-9914.

32 S. Zhang, C. Sun, J. Zeng, Q. Sun, G. Wang, Y. Wang, Y. Wu, S. Dou, M. Gao and Z. Li, Adv. Mater., 2016, 28, 8927-8936.

33 T. Yang, H. Ke, Q. Wang, Y. Tang, Y. Deng, H. Yang, X. Yang, P. Yang, D. Ling, C. Chen, Y. Zhao, H. Wu and H. Chen, ACS Nano, 2017, 11, 10012-10024.

34 A. Taylor, Biol. Trace Elem. Res., 1996, 55, 231-239.

35 W. Huang, H. Wu, X. Li and T. Chen, Chem.-Asian J., 2016, 11, 2301-2311.

36 J. D. Young, C. Crowley and E. M. Tucker, Biochem. Pharmacol., 1981, 30, 2527-2530.

37 Y. Fan, J. Yi, Y. Zhang and W. Yokoyama, Food Chem., 2018, 239, 1210-1218.

38 U. K. Gautam and C. N. R. Rao, J. Mater. Chem., 2004, 14, 2530-2535.

39 R. J. Turner, Y. Aharonowitz, J. H. Weiner and D. E. Taylor, Can. J. Microbiol., 2001, 47, 33-40.

40 E. Ju, K. Dong, Z. Chen, Z. Liu, C. Liu, Y. Huang, Z. Wang, F. Pu, J. Ren and X. Qu, Angew. Chem., Int. Ed. Engl., 2016, 55, 11467-11471.

41 Y. Yang, J. Tang, P. L. Abbaraju, M. Jambhrunkar, H. Song, M. Zhang, C. Lei, J. Fu, Z. Gu, Y. Liu and C. Yu, Angew. Chem., Int. Ed. Engl., 2018, 57, 11764-11769.

42 K. Ke, W. Yang, X. Xie, R. Liu, L. L. Wang, W. W. Lin, G. Huang, C. H. Lu and H. H. Yang, Theranostics, 2017, 7, 4763-4776.

43 Q. Fu, R. Zhu, J. Song, H. Yang and X. Chen, Adv. Mater., 2019, 31, 1805875.

44 Z. Yang, Y. Dai, C. Yin, Q. Fan, W. Zhang, J. Song, G. Yu, W. Tang, W. Fan, B. C. Yung, J. Li, X. Li, X. Li, Y. Tang, W. Huang, J. Song and X. Chen, Adv. Mater., 2018, 30, 1707509. 